\title{
RODA DE CONVERSA ENSINO REMOTO DE PROJETO DE AU EM CONTEXTO DE DISTANCIAMENTO SOCIAL - APRESENTAÇÃO
}

Por

VELOSO, MAISA

Editora-chefe (Moderadora)

CONVIDADOS (Professores doutores, por ordem de fala)

MONTEIRO, Ana Goes; CELANI, Gabriela; SILVA, Heitor de Andrade.

\section{EQUIPE DE APOIO TÉCNICO}

MEDEIROS, Renato; RODRIGUES, Clara; MEDEIROS, Luciana; CAVALCANTE, Eunádia; ALBUQUERQUE, Glauce.

\begin{abstract}
APRESENTAÇÃO
Dando continuidade aos debates do Grupo que faz a gestão desta Revista, aconteceu no dia 24 de setembro de 2020 (quarta-feira), das 17:00 às 19:00 horas (Brasília), a II Roda de Conversa Virtual "ENSINO REMOTO DE PROJETO DE AU EM CONTEXTO DE DISTANCIAMENTO SOCIAL". Ela foi organizada pelo Grupo PROJETAR, com cobertura e divulgação por meio da Revista PROJETAR - Projeto e Percepção do Ambiente Construído, ambos vinculados à Universidade Federal do Rio Grande do Norte, aproximando-se, mais especificamente, do Curso de Arquitetura e Urbanismo, do Programa de Pósgraduação em Arquitetura e Urbanismo (PPGAU) e do Programa de Pós-graduação em Arquitetura, Projeto e Meio Ambiente (PPAPMA). O evento foi disponibilizado ao vivo por meio do Facebook ${ }^{1}$ e do YouTube ${ }^{2}$, nesse último permanecendo on line para consulta.
\end{abstract}

A atividade focalizou uma temática contemporânea que repercutiu e tem repercutido fortemente sobre o ensino de projeto de Arquitetura e Urbanismo (AU): o ensino remoto. Embora até recentemente a área de AU não se mostrasse muito aberta ao ensino remoto como meio de desenvolvimento das relações ensinoaprendizagem, sobretudo em disciplinas de projeto, a pandemia e a necessidade de continuação do isolamento social exigiram mudanças em todos os campos do conhecimento e acabaram acelerando o processo de introdução dessa prática em nossos cursos de graduação. Assim, hoje, mesmo com suas ressalvas, os CAUs brasileiros estão oferecendo disciplinas em modalidade não-presencial, inclusive ateliers de projeto abarcando praticamente todas as temáticas e níveis de ensino. Os últimos meses têm gerado amplo debate acerca dessa modalidade educativa, sobretudo em termos teóricos. A Roda de Conversa propôs enfocar sobretudo questões práticas, ligadas a aspectos pedagógicos e metodológicos do ensino remoto em AU.

Sob essa perspectiva, nossa equipe enunciou algumas questões para fomentar o debate:

- Que elementos favorecem/limitam as experiências de ensino remoto no campo de AU, tornandoas mais/menos exitosas?

- Que estratégias/recursos poderiam tornar tais disciplinas adequadas, tanto ao contexto atual quanto à formação de um profissional capaz de enfrentar as questões-problema que se impõem ao nosso campo de atuação?

- Como, e até que ponto, as experiências didáticas que hoje estão acontecendo podem alterar a formação profissional e, consequentemente, o perfil do futuro arquiteto e urbanista? 
Convidamos três professores doutores na área de Arquitetura e Urbanismo para indicarem alguns caminhos para tal reflexão: Ana Goes Monteiro (na condição de Presidente da Associação Brasileira de Ensino de Arquitetura e Urbanismo - ABEA); Gabriela Celani (professora titular da Faculdade de Engenharia Civil, Arquitetura e Urbanismo da Universidade Estadual de Campinas - Unicamp); e Heitor Andrade Silva (Professor Adjunto do Departamento de Arquitetura da Universidade Federal do Rio Grande do Norte UFRN, representando o Grupo PROJETAR). Todos eles têm experiência de ensino, pesquisa e uma produção notável na área, com publicações em periódicos, livros, capítulos de livros e eventos.

O Encontro teve duração total de duas horas, destacando-se pela convergência e complementariedade de ideias dos participantes, pela rica diversidade de suas experiências e por ter propiciado uma importante troca de informações e argumentos. Ilustrando a situação vivenciada, a Figura 1 apresenta uma tela capturada ao final do encontro, reunindo os três professores palestrantes, a mediadora e os professores responsáveis pela organização e transmissão.

Figura 1: Imagem da II Roda de Conversa do Grupo Projetar.

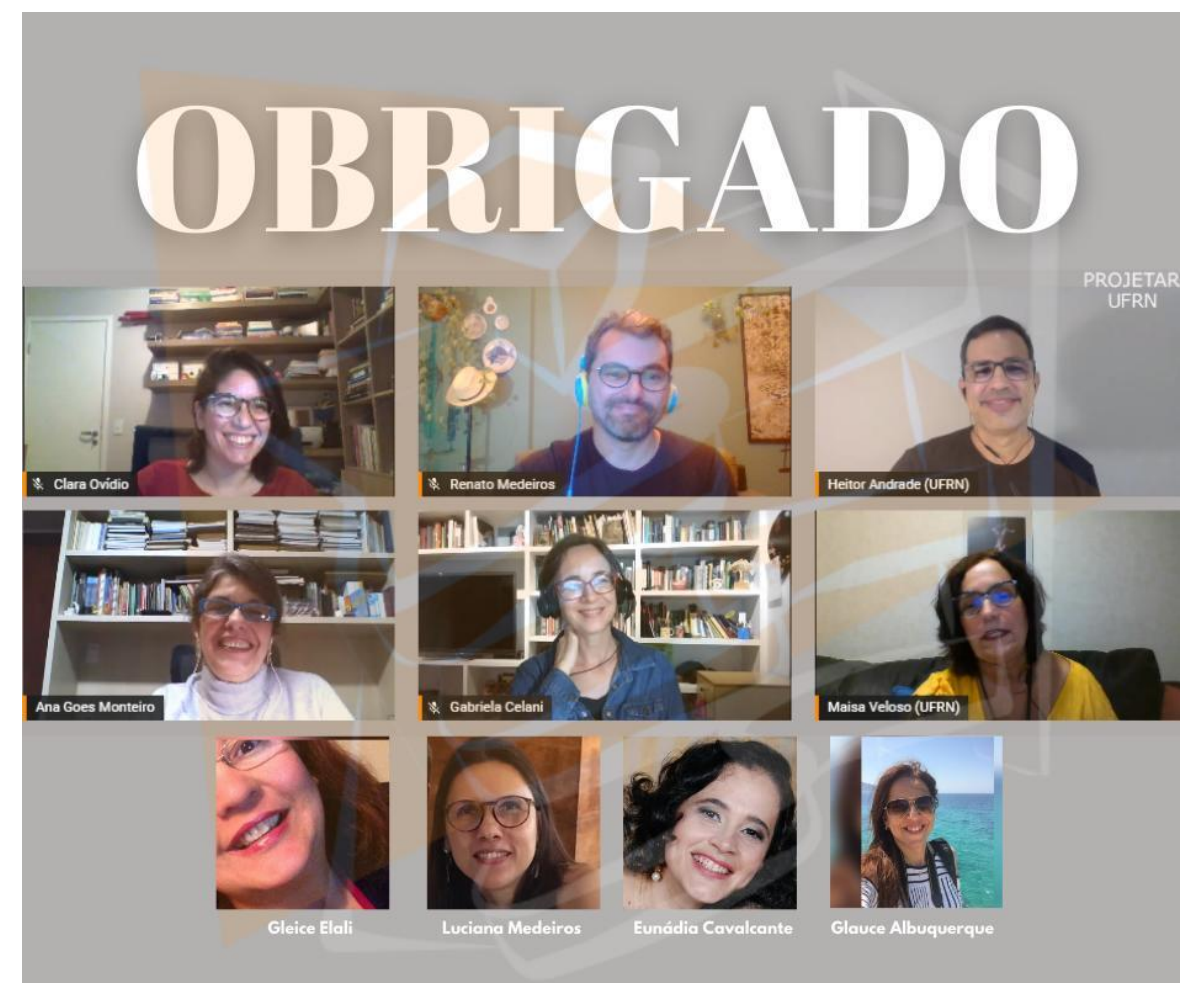

Fonte: Captura de tela (gerada a partir da plataforma StreamYard).

Da esquerda para a direita, na primeira linha, Clara Rodrigues e Renato Medeiros (da equipe técnica) e Heitor Andrade (palestrante); Na segunda linha, as palestrantes Ana Goes Monteiro e Gabriela Celani e a mediadora Maísa Veloso.

$\mathrm{Na}$ terceira linha, Gleice Elali, Luciana Medeiros, Eunádia Cavalcante e Glauce Albuquerque (comissão científica e gestão dos chats)

Após concluídas as preleções, os participantes passaram a responder perguntas da plateia virtual (inseridas nos chats do YouTube e do Facebook), as quais demonstraram o interesse dos espectadores pelas potencialidades e limites do ensino remoto do Projeto de AU e perspectivas para o futuro no contexto póspandemia. Os dos conteúdos das palestras são sintetizados a seguir pelos próprios autores.

\section{NOTAS}

${ }^{1}$ https://www.facebook.com/grupoprojetarufrn/videos/253380402610206

${ }^{2}$ https://www.youtube.com/watch?v=xO4RGhwiViQ\&t=533s 